\title{
Editorial
}

European

Thyroid Journal
Eur Thyroid J 2017;6:1-2

DOI: $10.1159 / 000457813$
Published online: February 8, 2017

\section{The European Thyroid Journal Reaches Its Sixth Year of Publication with Honours}

It is with some pride that we announce the European Thyroid Journal (ETJ) is now entering its sixth year of publication. Last year has been a very fruitful year for the ETJ. The number of submissions in 2016 increased by $30 \%$ compared to submissions in 2015 . Nevertheless, the time between submission and notice to authors of editorial decision did not increase and remained 41 days on average. To accommodate the increasing flow of submitted papers, we will increase the number of issues in 2017 from 4 to 6, meaning ETJ is becoming a bimonthly periodical. The number of pages in the 2017 volume 6 will increase by $17 \%$. Unavoidably the rejection rate, which is now just above $60 \%$, will rise further - at the same time allowing us to select even more strictly the best-quality papers for publication. In 2016 the journal earned a listing in the Emerging Sources Citation Index. The tragic death of Peter Laurberg, our associate editor for clinical thyroidology, was a great loss for the journal. Peter always promoted the journal, and actually it was his idea to start ETJ. We are fortunate in having Simon Pearce as his successor. Several new ventures started in 2016 to promote the journal even further, and they turned out to be rather successful. ETJ is now present on social media. An ultrashort synopsis of every individual paper, usually presented with a provocative question, is placed on Facebook frequently. We believe social media play an important role in how scientists and health care professionals obtain information about progress in science and changes in clinical practice. Social media might also be involved in author decisions regarding journal choice. So follow ETJ accounts on Facebook, Twitter, and Linkedin. The Annual Best Reviewer Award was presented for the first time at the European Thyroid Association annual meeting in September 2016 in Copenhagen. Criteria are the number of reviews, the quality of reviews, and the speed of reviews done for the journal. The award winner was Prof. Maria Alevizaki from Athens, earning a plaque as well as free registration and travel reimbursement for the Copenhagen meeting. The reviewer award is just one way in which we want to express our gratitude to all persons who act as reviewers for the journal. Their names for the year 2016 are listed below; one of them will be selected for the next Annual Best Reviewer Award. As I have said repeatedly before, fair but critical reviewers are essential to maintain the scientific quality of the journal at a high level.

Also on behalf of the associate editors Furio Pacini, Simon Pearce, Luca Persani, and Josef Koehrle, Wilmar M. Wiersinga Editor-in-Chief, European Thyroid Journal

\section{KARGER}

E-Mail karger@karger.com

www.karger.com/etj
(C) 2017 European Thyroid Association

Published by S. Karger AG, Basel 
Acknowledgement to Reviewers 2016

Maria Alevizaki

Stine Linding Andersen

Bjorn Åsvold

Thomas Bachleitner-Hofmann

Saba Balasubramanian

Luigi Bartalena

Taner Bayraktaroglu

D. Becu-Villalobos

Rocco Domenico Bellantone

Finn Noe Bennedbaek

Salvatore Benvenga

Bernadette Biondi

Sofie Bliddal

Fausto Bogazzi

Steen Bonnema

Georg Brabant

Gabriela Brenta

Bekir Cakir

Luis Carvajal-Carmona

Maria Grazia Castagna

Ethem Turgay Cerit

T. Cheetham

Iacopo Chiodini

Luca Chiovato

R. Conrad

David Cooper

Bernard Corvilain

Stephanie Cox

Liviu Danescu

Mario de Felice

Harald Dobnig

Quan-Yang Duh

Leonidas Duntas

Creswell Eastman

Grigoris Effraimidis

Rosella Elisei

Erik Endert
Murat Erdogan

Valentin Fadeyev

Ulla Feldt-Rasmussen

Sebastiano Filetti

Emilio Fiore

Laura Fugazzola

Dagmar Führer

Roland Gartner

Melanie Geer

Anthony Gerdes

Carol Greenlee

Laszlo Hegedus

Zeliha Hekimsoy

Arturo Hernandez

Shih-Ming Huang

Paolo Innocenti

Carolina Janovsky

George Kahaly

Jasper Karmisholt

Peter Kopp

Tim Korevaar

Z. Krukowski

John Lazarus

Diana Learoyd

Mohamad Maghnie

Anna Luiza Maia

Claudio Marcocci

Marco Medici

Miguel Melo

Carla Moran

Roberto Negro

Marek Niedziela

Yuri Nikiforov

Mikael Nilsson

Helena Filipsson Nystrom

Antonella Olivieri

Fabio Orlandi
Enrico Papini

Ralf Paschke

Richard Payne

Petros Perros

Agnieszka Piekielko-Witkowska

Fabian Pitoia

Kris Poppe

Salman Ravzi

S.J. Richardson

Pedro Rosario

Lawrence Roth

Marek Ruchala

Martin Schlumberger

Lutz Schomburg

M. Schupp

Tarun Sekhri

Hiroki Shimura

Manuela Simoni

Peter Smyth

Steven Soldin

Marius Stan

David Steward

Hugo ten Cate

Linda Thienpont

O. Torring

Fernanda Vaisman

Mark Vanderpump

Paul van Trotsenburg

Theo Visser

Paolo Vitti

Robert Wagner

Anthony Weetman

Jean-Louis Wemeau

Alison Wilson

Shunichi Yamashita

Kiyoshi Yamauchi

Michael Zimmermann 